\title{
Dominance and context effects on activation of alternative homophone meanings
}

\author{
Lillian Chen ANd Julie E. Boland \\ University of Michigan, Ann Arbor, Michigan
}

\begin{abstract}
Two eyetracking-during-listening experiments showed frequency and context effects on fixation probability for pictures representing multiple meanings of homophones. Participants heard either an imperative sentence instructing them to look at a homophone referent (Experiment 1) or a declarative sentence that was either neutral or biased toward the homophone's subordinate meaning (Experiment 2). At homophone onset in both experiments, the participants viewed four pictures: (1) a referent of one homophone meaning, (2) a shape competitor for a nonpictured homophone meaning, and (3) two unrelated filler objects. In Experiment 1, meaning dominance affected looks to both the homophone referent and the shape competitor. In Experiment 2, as compared with neutral contexts, subordinatebiased contexts lowered the fixation probability for shape competitors of dominant meanings, but shape competitors still attracted more looks than would be expected by chance. We discuss the consistencies and discrepancies of these findings with the selective access and reordered access theories of lexical ambiguity resolution.
\end{abstract}

Intuition suggests that we normally settle on the appropriate meaning of a lexically ambiguous word immediately if the context is sufficiently informative-for example, Chris needed some money, so he went to the bank. In fact, a large number of experimental studies have demonstrated that sentence context influences the timing and/or degree to which the alternative meanings are activated (e.g., Dopkins, Morris, \& Rayner, 1992; Lucas, 1999; Sereno, Brewer, \& O’Donnell, 2003; Tabossi, 1988). However, the relative frequency of the alternative meanings is also clearly important. When presented in a neutral sentence context, the more frequent, dominant meaning of an ambiguous word is activated more quickly and persists longer than less frequent, subordinate meanings (e.g., Simpson \& Burgess, 1985; Simpson \& Krueger, 1991).

Most of the current debate in the domain of lexical ambiguity resolution rests on the fate of the dominant meaning when the context supports the subordinate meaning. The reordered access account of Duffy, Morris, and Rayner (1988) maintains that both the subordinate meaning (activation boosted by context) and the dominant meaning (activated due to its frequency) compete for selection. Thus, in contexts supporting subordinate meanings, reading times for ambiguous words are long, as compared with those for an unambiguous control word that is matched in corpus frequency to the overall frequency of the ambiguous word. This is the subordinate bias effect that has been reported in numerous reading experiments (Binder, 2003; Binder \& Rayner, 1998; Kambe, Rayner, \& Duffy, 2001; Pacht \& Rayner, 1993; Rayner, Cook, Juhasz, \& Frazier, 2006; Rayner, Pacht, \& Duffy, 1994; Sereno, O’Donnell, \& Rayner, 2006; Sereno, Pacht, \& Rayner, 1992).
The subordinate bias effect is a well-established phenomenon under two conditions: (1) The homograph is strongly polarized, with subordinate meanings retrieved only about $10 \%$ of the time in word association tasks, and (2) reading time for the homograph in the subordinate context is compared with that for an unambiguous word matched to the homograph's form frequency - that is, the sum of all meaning frequencies. When these conditions are not met, the results have been less consistent. For example, Wiley and Rayner (2000) did not find a subordinate bias effect, using ambiguous words that were not strongly polarized and context passages that made use of titles for disambiguation. And Sereno et al. (2006, Experiments 2 and 3) actually found the reverse pattern when using a meaning frequency control word: Reading times were shorter for highly polarized homographs in strong subordinate-biased contexts, as compared with those for a control word that was matched in frequency with the subordinate meaning of the homograph. This finding seems to suggest that only the subordinate meaning of the homograph was accessed, but it is unclear why reading times for the homographs were shorter than those for control words; the authors themselves simply speculate and recommend further research. Sereno et al. (1992), who also failed to find the standard subordinate bias effect, argued that a meaning frequency control word is more appropriate than a form-matched control word, because the latter contrasts a high-frequency (control) word with a low-frequency word (the subordinate meaning of the homograph).

The issue of the appropriate control word is critical, although it is difficult to resolve because both word form frequency and word meaning frequency are likely to im- 
pact reading time. Furthermore, the fact that the subordinate bias effect is so dependent on comparison against a high-frequency control word raises the concern that the subordinate bias effect does not reflect competition between meanings after all but, rather, reflects the increased time it takes to access and integrate a lower frequency word (as in Reichle, Pollatsek, \& Rayner, 2007; Reichle, Rayner, \& Pollatsek, 2003). Reichle et al. (2007) suggested that the subordinate bias effect can be modeled in two ways. In their preferred account, longer reading times for the subordinate-biased homograph are due to competition from the dominant meaning. Because both meanings are activated and in competition, this is consistent with the reordered access model (Duffy, Kambe, \& Rayner, 2001; Duffy et al., 1988). Reichle et al. (2007) also considered an account in which longer reading times for the subordinate-biased homograph are due to its low frequency, as compared with the high-frequency control word. Such an account is consistent with selective activation of the subordinate meaning only, because it provides an explanation of the subordinate bias effect without reference to activation of the dominant meaning.

During the last 15 years, Kellas and colleagues have advocated a context-sensitive or selective access account in which the dominant meaning is not activated if the context is sufficiently constraining toward a subordinate meaning. Evidence from lexical decision, naming, and self-paced reading studies has demonstrated that in strongly biasing contexts, reaction times to contextually appropriate items are facilitated but reaction times to contextually inappropriate meanings are not (Kellas, Martin, Yehling, Herman, \& Vu, 1995; Kellas \& Vu, 1999; Martin, Vu, Kellas, \& Metcalf, 1999; Simpson, 1981; Vu \& Kellas, 1999; Vu, Kellas, Metcalf, \& Herman, 2000; Vu, Kellas, \& Paul, 1998; Vu, Kellas, Petersen, \& Metcalf, 2003).

In short, the fate of the dominant meaning in a strong subordinate context is a theoretically important question that differentiates two possible accounts of the subordinate bias effect and, more generally, distinguishes between the reordered access and the selective access accounts of lexical ambiguity resolution. The issue is whether top-down contextual cues can override the strong relationship between the word form of an ambiguous word and its dominant meaning. This issue applies to both reading and listening paradigms. In fact, in much of the groundbreaking research, spoken homophones have been used in a cross-modal paradigm, leading to the conclusion that multiple meanings are accessed, even in biasing contexts (e.g., Onifer \& Swinney, 1981; Swinney, 1979; Tabossi, 1993; Tabossi, Colombo, \& Job, 1987; Tanenhaus, Leiman, \& Seidenberg, 1979). More recently, Huettig and Altmann (2007) found evidence that the dominant homophone meaning is activated in a subordinate-biased context, using a variant of the visual world paradigm introduced by Tanenhaus, SpiveyKnowlton, Eberhard, and Sedivy (1995).

We will take some time to review Huettig and Altmann's (2007) second experiment, both because of its similarity to the present set of experiments and because it provides quite dramatic evidence of dominant meaning activation in a subordinate context. Participants heard sentences contain- ing polarized homophones, such as pen, while viewing an array of four line drawings. The drawings appeared $1 \mathrm{sec}$ before sentence onset in all conditions. In the neutral condition, the sentence contexts were neutral as to the meaning of the homophone, such as The man got ready quickly, but then he checked the pen. In the biased condition, the sentence contexts supported the subordinate meaning of the homophone - for example, The welder locked up carefully, but then he checked the pen. In the neutral and biased conditions ( $25 \%$ of the trials), the participants saw drawings depicting both meanings, along with two unrelated distractors. In the competitor condition, the participants heard the subordinate-biased context sentence while a visual shape competitor (a sewing needle) replaced the dominant meaning (writing pen) (for evidence that looks to how visual shape competitors track lexical access, see Dahan \& Tanenhaus, 2005; Huettig, Gaskell, \& Quinlan, 2004).

At homophone onset (before lexical access of the homophone had begun), Huettig and Altmann (2007) found no differences in looks to any objects in the neutral condition. However, in the biased and competitor conditions, the listeners were already fixating the pen enclosure drawing $45 \%$ and $49 \%$ of the time, respectively, indicating that they had used the sentence context to fixate on sentencerelevant drawings.

At homophone offset, both dominant and subordinate referents were fixated more than were fillers in both the neutral and the biasing conditions. In the neutral condition, presumably both meanings of the homophone were accessed, due to support from two sources: the spoken word form and the images of two potential referents in the visual display. It is not possible to know for sure that meaning activation for the homophone was influenced by the visual display in this condition, but it seems likely, especially for the subordinate meaning. In the biased condition, the combination of sentence context and the visual display apparently activated the subordinate meaning prior to any phonological cues from the spoken homophone. Nonetheless, it is striking that the spoken word form of the homophone still prompted looks to the dominant, but contextually inappropriate, referent. Even more striking is the fact that the pattern in the competitor condition was very similar to that in the biased condition, even though the dominant referent was replaced with a shape competitor. Looks to the shape competitor for the dominant meaning can be taken as evidence that the dominant meaning was activated, despite the subordinate context and the lack of an appropriate visual referent. Thus, this experiment provides very strong evidence for dominant meaning activation, even when a subordinate-biased context has successfully focused attention on the subordinate meaning.

The Huettig and Altmann (2007) findings provide compelling evidence that the word form of a polarized homophone will always activate the dominant meaning, regardless of the linguistic and visual context. This begs the question: Does the linguistic context have any effect on the activation of the dominant meaning? According to the reordered access account, a subordinate-biased context can boost activation of the subordinate meaning, thereby making the dominant meaning and the subordinate meaning 
more competitive. But this does not entail delaying and/or limiting activation of the dominant meaning. The reordered access model maintains that "prior disambiguating context does affect the access process by increasing the availability of the appropriate meaning without influencing the alternative meaning" (Duffy et al., 1988, p. 431). The same point has been made more recently: "The two meanings became activated independently. While context could speed activation of the intended meaning, it had no effect on the speed of activation of the unintended meaning" (Rayner, Binder, \& Duffy, 1999, p. 847). Thus, in subordinate-biasing contexts, activation of the dominant meaning should be unaffected, whereas the subordinate meaning should be activated earlier than usual. On the other hand, for selective access accounts, the activation of the meanings of an ambiguous word depends on several constraints: frequency, type of context, and strength of context. The combined influence of these variables determines the meaning accessed (Martin et al., 1999). Thus, the subordinate-biasing context would serve to both boost activation of the subordinate meaning and limit activation of the dominant meaning.

In the present experiments, we used a visual world paradigm similar to that in Huettig and Altmann (2007) and began by establishing the extent of meaning activation for subordinate and dominant meanings of homophones in a neutral context (Experiment 1). Then we manipulated the linguistic context to determine how activations of both the subordinate and the dominant meanings would be affected (Experiment 2). As in Huettig and Altmann's competitor condition, we used visual displays that contained an actual referent for the subordinate meaning, a shape competitor for the dominant meaning, and two unrelated distractors. One major difference between our experiments and theirs is that we did not present the visual display until homophone onset, in order to prevent the visual display from influencing the initial stages of spoken word recognition.

\section{EXPERIMENT 1}

In Experiment 1, we explored dominance effects on the activation of multiple meanings of ambiguous words in an instructional eyetracking-during-listening task. This was somewhat analogous to the neutral condition in Huettig and Altmann (2007), described above, but there were three important differences. First, instead of using a declarative sentence, we used imperatives that directly engaged the listener (Look at the flower/flour), in the tradition of Dahan, Magnuson, and Tanenhaus (2001). Second, we presented the visual stimuli coincident with the onset of the target word (a homophone in our experiments), rather than at trial onset, in order to limit the degree to which the visual context would constrain lexical activation. Our goal in making these changes was to get a clearer picture of the time course and extent of activation for the dominant and subordinate meanings, as reflected by fixation patterns in this paradigm, when meaning frequency was the only relevant factor.

Third, rather than presenting two meanings of the polarized homophones directly, one meaning was depicted using an actual referent picture, and the other meaning was depicted by a visual shape competitor (Dahan \&
Tanenhaus, 2005; Huettig et al., 2004). For example, the dominant meaning of the homophone flower/flour was directly depicted using a picture of a flower, and the subordinate meaning was indirectly depicted using a pillow as a visual shape competitor for flour. On another trial, the subordinate meaning of flower/flour was depicted using a picture of flour, and a lollipop was used as a shape competitor for the dominant meaning (flower). Although an actual referent of the homophone was always in the visual display, residual activation of the alternative meaning of the homophone could be assessed by analyzing the looks received by the shape competitor. As in Dahan and Tanenhaus, none of the shape competitors overlapped in phonology with the spoken referent names, so any activation of the shape competitor from the spoken input indicated activation of its homophone referent. The activation of multiple meanings of the ambiguous word was measured by comparing looks to the shape competitor picture on trials in which the dominant- or the subordinate actual item was pictured. A relative dominance effect would be found if pictures of the dominant meanings of a homophone attracted more looks than did pictures of the subordinate meanings. Because we needed to compare the probability of looking at two different pictures, it was crucial to match the pictures on various dimensions, as described in our normative measures below.

\section{Method}

\section{Participants}

Thirty undergraduates at the University of Michigan participated in this experiment for partial course credit in an introductory psychology class. All the participants in this and the following experiments were native speakers of English and had normal or correctedto-normal vision.

\section{Materials}

We collected word association norms for a set of heterographic and homographic homophones (details below) and chose the 14 homophones for which meaning dominance was most polarized. Each homophone had two distinct, imageable meanings (see Appendix A).

The auditory stimuli were recorded by a female speaker: "Look at the cross. Now look at the (homophone)." For each digital speech file, silence was added before the onset of the spoken instructions as needed (i.e., before "Look at ..."), so that the onset of each critical homophone was $3,000 \mathrm{msec}$ from the beginning of the auditory stimulus.

For each meaning of each homophone, two critical pictures were selected. One depicted the referent of the homophone (actual referent), and one depicted an object that was similar in shape to the homophone referent (shape competitor). The norms used to assess shape similarity will be described below.

Visual stimuli consisted of four pictures arranged on a white background with a fixation cross in the center for each critical trial. The critical pictures were all full-color realistic images selected from an online searchable database of images (Google Image Search, 2004). Actual referent images were chosen so that the picture represented a typical instance or instances of the object and so that the picture would not be identified with other possible labels. For example, a stamp with an unknown design was chosen so that the participants would not identify the stamp with its design, such as an American flag. In the case of letter, the actual referent included multiple letters in order to prevent the picture from being labeled as the letter itself, such as "B." Shape competitor images were selected so that the picture was as identifiable as the actual referent and would not be assigned a label that overlapped in phonology or semantics. The 
pictures appeared in the upper left, upper right, lower left, or lower right quadrant, arranged so that the actual referent appeared in each quadrant an equal number of times for every participant. The shape competitor also appeared in each quadrant an equal number of times for every participant. The two remaining quadrants contained filler pictures of objects with unambiguous names that did not begin with the same phonemes as the critical homophones and with shapes that were not similar to those of the objects in the critical pictures.

Each homophone was tested only once, with each auditory stimulus occurring with one of two visual display types: dominant actual or subordinate actual. In the dominant actual display, the participants viewed the actual referent of the dominant meaning of the homophone, together with the shape competitor of the subordinate meaning of the homophone. In the subordinate actual display, the participants viewed the actual referent of the subordinate meaning of the homophone, together with the shape competitor of the dominant meaning of the homophone. Display type was varied between participants because we were concerned that the shape competitors would get relatively few looks, and we wanted to maximize statistical power for comparisons evaluating the hypothesis that shape competitors received more looks than would be expected by chance. Each participant was randomly assigned to one of the two display types.

In addition to the 14 critical homophone trials, 14 filler trials with unambiguous targets were constructed. The trials were presented in a fixed random order.

\section{Norming}

Word association norms. Meaning dominance frequencies were collected in a word association task. Twenty-seven participants provided the association norms and received partial course credit. No participants in this or any of the norming experiments participated in the primary experiment. The participants listened to a list of words and, for each word, typed the first related word that came to mind. The stimuli consisted of 148 heterographic and homographic homophones and 80 unambiguous fillers. We selected 14 homophones that elicited word association responses with at least a $19 \%$ difference between the dominant and the subordinate meanings. Of these 14 homophones, on average, the dominant meaning gathered $79 \%$ of the total word association responses, and the subordinate meaning gathered $16 \%$ of the total responses. The remaining $5 \%$ of the responses had missing values or were unrelated to the two most common meanings of the homophone.

Picture agreement norms on actual referents. Picture agreement norms confirmed that there was no difference in labeling agreement for the pictures we chose to represent the actual referents of the subordinate and dominant meanings of the homophones. Each of 42 participants was presented with a sequence of 200 pictures on a computer screen. Two lists were created so that half of the homophone pictures were of the dominant meaning and half of the homophone pictures were of the subordinate meaning. Each participant saw each homophone item once, in either the dominant or the subordinate condition. Only 1 picture appeared on each screen, simultaneously with a box in which the participant was asked to type the name of the picture of the object represented. Fourteen were pictures of homophones, and 186 were filler pictures with unambiguous labels. Trials were coded as having correct agreement when the response included the homophone in any part of the answer, including misspelled words and plurality differences, but not including synonyms or other names. For example, if the intended label was flower, responses such as purple flower, flower petals, flowers, and flowr were accepted. However, responses such as orchid, purple bloom, and bouquet were not accepted. The agreement between the participants' responses and the intended labels was $85.5 \%$ for the dominant-biased condition and $81.2 \%$ for the subordinatebiased condition. A $t$ test indicated no differences between the conditions $\left[t_{2}(26)=0.76, p>.10\right]$

Picture norms on shape competitors. In choosing the pictures to represent the shape competitors, it was not crucial to select pictures with high name agreement, because the relevant factor was shape similarity to a prototypical object representing one of the homophone's meanings. Nonetheless, it would present a confound if a shape competitor picture was likely to be labeled with a name beginning with the same phonemes as the homophone in that particular trial. This is actually a potential weakness of Huettig and Altmann's (2007) competitor condition, described above, because they provided no norms for the shape competitors to ensure that they would not be given a label that overlapped in phonology with the homophone. We worried that, for example, the shape competitor needle from their example sentence would activate pin - a phonological competitor for pen.

Thus, the norms with which we collected picture-naming data for the shape competitor pictures were similar to the labeling agreement norms for the actual referent pictures. Twenty participants were presented with a sequence of 128 pictures on a computer screen. One list was created with 14 competitors of the dominant meanings and 14 competitors of the subordinate meanings of the homophones. One hundred filler pictures with unambiguous names were used. Each participant saw every shape competitor once, in both the dominant and the subordinate conditions. Only 1 picture appeared on each screen, simultaneously with a box in which the participant was asked to type the name of the picture of the object represented. No responses for the shape competitor pictures indicated any phonological similarity to the homophone to which the shape competitor belonged.

Picture similarity norms. Picture similarity norms indicated that the shape competitors were, in fact, similar in shape to the actual referents. Twenty-four participants were presented with a series of pictures with accompanying questions, such as "How similar in shape is this object to a flower?" The participants were asked to rate, on a scale of 1 (not similar) to 7 (very similar), how similar the presented picture was to the object mentioned in the question. The participants' judgments may also have been influenced by other perceptual variables, such as color and texture, but we explicitly avoided pictures with any conceptual or instrumental relationships to the homophones. In addition to the 28 shape competitor trials, there were 25 filler trials in which participants were asked to evaluate the shape similarity of a picture to a concept that we judged to be either related or unrelated in shape. The participants rated every shape competitor once. The mean ratings for shape similarity were 4.84 and 5.76 for dominant and subordinate shape competitors, respectively. It was revealed by $t$ tests that dominant shape competitors were judged less similar in shape to the actual objects than were subordinate items, so any looks to dominant shape competitors cannot have been due to the higher similarity of those items to the actual objects $\left[t_{1}(1,23)=7.32, p<.001 ; t_{2}(1,26)=3.50, p<.05\right]$.

Picture saliency norms. Picture saliency norms were conducted to evaluate any difference in saliency among the critical pictures. These norms were collected for all 16 critical trials used in Experiment 2; however, only the 14 trials relevant to Experiment 1 will be reported here. Thirty-five participants were asked to view pictures silently on the computer screen while a head-mounted eyetracker monitored their eye movements. Two display conditions were created such that half the participants saw the dominant actual referents and the subordinate shape competitor, and the other half saw the subordinate actual referents and the dominant shape competitor. On each trial, four pictures appeared on the screen for $5 \mathrm{sec}$, and a drift correction procedure was conducted between every trial. The four pictures were the same as the pictures in Experiment 1. The critical trials and 28 filler trials were presented in a random order.

The dwell time percentages for each object type in the dominant actual display condition were the following: actual referent, $19.1 \%$; shape competitor, $20.1 \%$; filler objects, $18.7 \%$. For the subordinate actual display, they were: actual referent, $21.2 \%$; shape competitor, $18.9 \%$; filler objects, $18.5 \%$. For shape competitors and filler objects, independent $t$ tests showed no differences between the dominant actual and the subordinate actual display conditions [shape competitor, $t_{1}(1,33)=1.04, p>.10$, and $t_{2}<1$; filler, $t_{1}<1$, $\left.t_{2}<1\right]$. For actual referents, there was a marginal effect only by participants $\left[t_{1}(1,33)=-1.83, p<.10 ; t_{2}<1\right]$, in which subordinate referents attracted more fixations. Independent $t$ tests showed no advantage of shape competitors, as compared with fillers, in the 
dominant actual display $\left[t_{1}(1,52)=1.17, p>.10 ; t_{2}<1\right]$ or in the subordinate actual display $\left(t_{1}<1 ; t_{2}<1\right)$. Thus, there were no advantages in saliency for pictures representing the dominant meanings over pictures representing the subordinate meanings or for shape competitors over filler objects.

\section{Procedure and Equipment}

The auditory sentences and their corresponding slides were presented in a fixed random order. There were four practice trials before the experimental trials began. Eye position was recorded as the participants listened to the sentences, using an ISCAN head-mounted eyetracking system. The eye and scene cameras were mounted on a headgear, with a sampling rate of $120 \mathrm{~Hz}$.

The participants were seated approximately 24 in. from the screen. The visual angle from the fixation cross to the pictures was approximately $9^{\circ}$. The auditory and visual stimuli were presented using E-Prime software. The participants heard these instructions:

At the beginning of each trial, you will see a cross in the center of the screen. Surrounding the cross, there will be four pictures.

You will hear instructions that will ask you to look at the cross and then point to objects on the screen.

Before the practice trials, a 6-point calibration slide was presented. On each trial, the participants were presented with a fixation slide simultaneously with auditory sentence instructions. At 3,000 msec after sentence onset, the four-picture slide appeared simultaneously with the onset of the critical homophone. The experimenters used the scene camera screen to verify whether or not the participants were accurately pointing to the correct targets. Between each trial, there was an additional 6-point calibration slide. If 4 out of 6 points were not accurately calibrated, recalibration was performed. The entire experiment lasted less than $30 \mathrm{~min}$.

The data were collected and organized using PRZ analysis software provided by ISCAN.

\section{Results}

As was noted above, there were two critical pictures on each trial: the actual referent and the shape competitor. The data for one item were omitted from all the analyses, because the subordinate meaning was inadvertently pre- sented in the dominant actual display. Four eye movement measures were analyzed: (1) first-run dwell time on each of the critical pictures and filler objects; (2) visual bias toward shape competitors, measured by log gaze probability ratios to shape competitor and filler objects from target word onset until 1,000 msec after target onset; (3) the latency of the first look to the critical picture after target onset; and (4) the number of trials with at least one look to the shape competitor.

Figure 1 presents the proportions of looks to all four types of critical pictures during each 100 -msec interval after homophone onset, for both display conditions. From 0 to $399 \mathrm{msec}$, the participants were not looking at any critical pictures $99 \%$ of the time. Beginning at $400 \mathrm{msec}$, the participants started fixating the critical pictures. The dominant actual referents appear to have attracted more looks over time than did the subordinate actual referents, revealing a relative dominance effect. Looks to shape competitors appear to have increased at the same time as those to the actual referents, with dominant shape competitors attracting more looks than did subordinate shape competitors. Looks to the subordinate shape competitors decreased starting around $700 \mathrm{msec}$.

\section{First-Run Dwell Time}

First-run dwell time was analyzed in order to evaluate initial processing time for each of the fixated objects (as in Arai, Van Gompel, \& Scheepers, 2007). First-run dwell time was defined as the first and all consecutive fixations on an object until another object or background was fixated. To maximize the likelihood that there would be at least one fixation on all four pictures for most trials, we searched for fixations during a large time window, $5 \mathrm{sec}$ following target onset. The mean first-run dwell times (in milliseconds) for the critical objects in the dominant actual display (with standard errors) were as follows: actual ref-

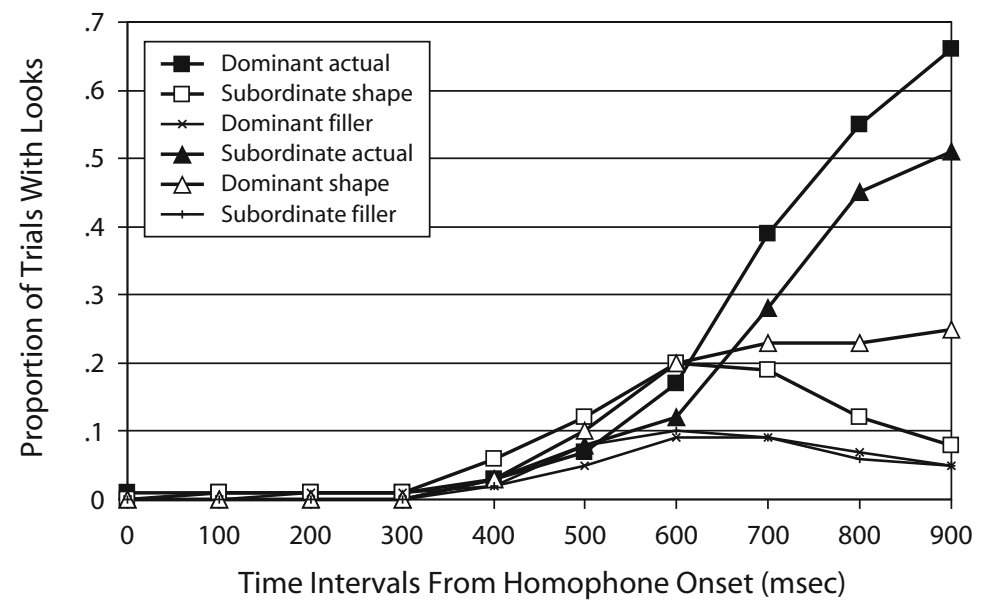

Figure 1. Time course of probability of fixations on critical pictures and fillers at each 100-msec interval from homophone target onset for combined dominant actual (represented with squares) and subordinate actual (represented with triangles) display conditions. The first time interval is $0-99$ msec after homophone onset. 
erent, 950 (35), shape competitor, 174 (15), filler objects, 134 (7). The means for the subordinate actual display were as follows: actual referent, 872 (38), shape competitor, 360 (36), filler objects, 164 (12).

In order to determine whether the second meaning of the homophones was activated at above-chance levels, first-run dwell times for the shape competitors were compared with mean first-run dwell times for the filler objects. For each display condition, an independent $t$ test was performed. For the dominant actual display, subordinate shape competitors had longer first-run dwell times than did fillers $\left[t_{1}(1,28)=2.30, p<.05 ; t_{2}(1,23)=2.67, p<\right.$ $.05]$. For the subordinate actual display, dominant shape competitors had longer first-run dwell times than did fillers $\left[t_{1}(1,27)=4.70, p<.001 ; t_{2}(1,24)=2.28, p<.05\right]$. These findings suggest that both the dominant and the subordinate meanings, represented by the shape competitors, were activated at levels higher than chance. This is not surprising, given the neutral linguistic context and the results of Huettig and Altmann (2007), but it demonstrates activation of the subordinate meaning of a homophone even when a subordinate referent is not viewed prior to homophone onset.

Display condition effects on the first-run dwell times to actual referents and shape competitors were analyzed using independent $t$ tests. There was no effect of display condition on actual referents $\left[t_{1}(1,28)<1 ; t_{2}(1,24)=\right.$ $1.11, p>.10]$. However, shape competitors showed a significant effect of meaning dominance by participants and a marginal effect by items $\left[t_{1}(1,28)=3.91, p<.001\right.$; $\left.t_{2}(1,24)=2.01, p<.10\right]$.

\section{Visual Bias Toward Shape Competitors}

To evaluate the time course of activation of the second meaning of ambiguous words, visual bias toward the shape competitor, as compared with the filler objects, was analyzed in 100 -msec intervals from target word onset until $1 \mathrm{sec}$ after target onset. As per Arai et al. (2007), log gaze proportions were used in order to circumvent problems of interdependence between looks to pictures. If an actual referent is fixated $70 \%$ of the time in Condition A and 50\% of the time in Condition B, the shape competitor automatically has a lower chance of being fixated in Condition A than in B, purely as a consequence of being paired with an object that attracts more fixations. Thus, it is not appropriate to compare absolute proportions of looks to different pictures on the same trial. Log gaze proportions provide a measure of bias toward the shape competitor, independently of the proportion of fixations to the actual referent, providing an appropriate measure of higher-than-chance activation. Because filler objects should not attract fixations when the homophone is spoken and should only be fixated by chance, any bias toward shape competitors over filler objects would indicate preferential processing of the dominant meaning.

We used Arai et al.'s (2007) formula for log ratios to evaluate the strength of visual bias toward shape competitors:

$$
\ln [P(\text { Shape Competitor }) / P(\text { Filler Objects })] \text {. }
$$

$P$ (Shape Competitor) is the likelihood that the shape competitor will be fixated during the $100-\mathrm{msec}$ interval, and $P$ (Filler Objects) is the likelihood that a filler object will be fixated during the 100-msec interval. Using the log of the ratio of likelihoods yields a number that is 0 , positive (indicating a shape competitor visual bias), or negative (indicating a filler object visual bias). Note that there are missing values for several log-ratio values, due to zero values at the early bins: No ratio can be determined using zero as a denominator or a $\log$ value for zero. Figure 2 plots log gaze ratios in $100-\mathrm{msec}$ intervals, relative to homophone onset. Due to missing values, statistics could be computed only by starting from the 500-msec interval.

For each display condition, one-way ANOVAs comparing the log ratio with the test value 0 were performed within participants and within items for each $100-\mathrm{msec}$ interval from 500 until $1,000 \mathrm{msec}$ after target onset. The degrees of freedom change for the different analyses on the basis of the number of zero probabilities on a trial by participants or items. These differences in degrees of

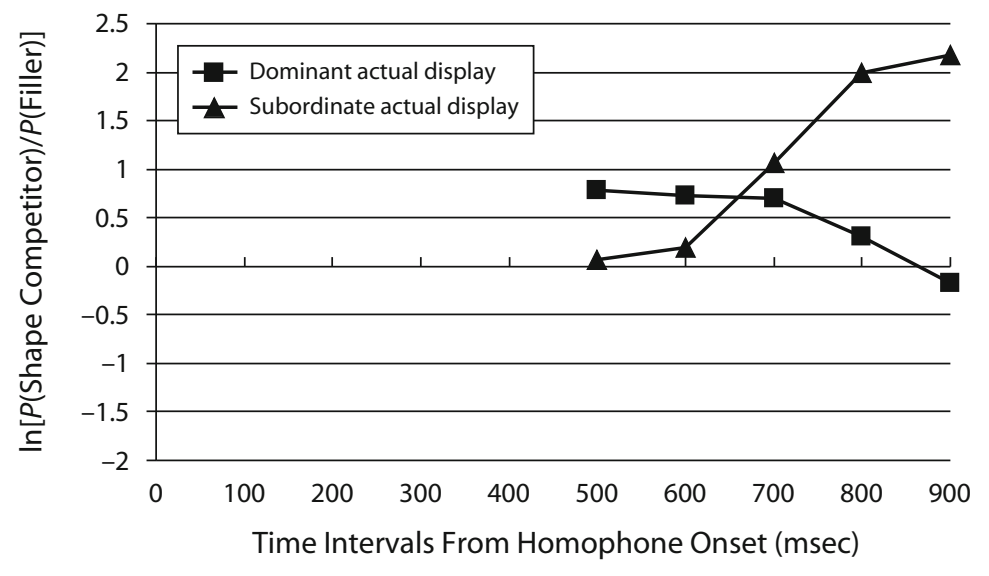

Figure 2. Visual bias toward shape competitors as indicated by log gaze ratios in 100-msec time intervals, by dominant actual and subordinate actual display conditions. The first time interval is $\mathbf{0}-\mathbf{9 9} \mathbf{m s e c}$ after homophone onset. 
freedom across intervals affect the strength of the ANOVA $F$ values, so that lower means can produce more significant $F$ values if they have more degrees of freedom.

For the dominant actual display condition, there was a visual bias toward the subordinate shape competitors at the 500-msec interval $\left[F_{1}(1,14)=8.43, p<.05\right.$; $\left.F_{2}(1,12)=7.60, p<.05\right]$. This bias was significant at the 600 -msec interval by items, was marginal by participants $\left[F_{1}(1,16)=4.18, p<.10 ; F_{2}(1,18)=14.31, p<.01\right]$, and was fully significant again at $700 \mathrm{msec}\left[F_{1}(1,24)=\right.$ $\left.10.73, p<.01 ; F_{2}(1,16)=8.77, p<.01\right]$. For the subordinate actual display condition, there was a visual bias toward the dominant shape competitors at the 500-msec interval by participants, which was marginal by items $\left[F_{1}(1,16)=11.94, p<.01 ; F_{2}(1,18)=3.72, p<.10\right]$, that was fully significant from 600 to $1,000 \mathrm{msec}$ after target onset $\left[600 \mathrm{msec}, F_{1}(1,20)=15.00, p<.01\right.$, and $F_{2}(1,24)=7.21, p<.05 ; 700 \mathrm{msec}, F_{1}(1,22)=17.02$, $p<.001$, and $F_{2}(1,20)=16.73, p<.01 ; 800 \mathrm{msec}$, $F_{1}(1,20)=33.29, p<.001, F_{2}(1,16)=29.64, p<.001$; $900 \mathrm{msec}, F_{1}(1,20)=39.35, p<.001 ; F_{2}(1,16)=46.53$, $p<.001]$. In sum, the activation of the second meaning, as indexed by the visual bias toward the shape competitor, as compared with filler objects, was evident for both the dominant and the subordinate meanings at the earliest measurable time frame; however, the dominant meaning seems to have had a more robust activation that lasted longer than that of the subordinate meaning.

To determine whether the likelihood of fixating the shape competitors in a given interval depended on whether it represented the dominant meaning or the subordinate meaning, we performed $t$ tests on the log ratios of shape competitors, as compared with filler objects, at each 100msec interval. Display condition effects appeared only at $800 \mathrm{msec}$, where there was a stronger visual bias toward the dominant shape competitor than toward the subordinate shape competitor [800 msec, $t_{1}(1,19)=2.77, p<$ .05 , and $t_{2}(1,14)=3.01, p<.01 ; 900 \mathrm{msec}, t_{1}(1,17)=$ $4.00, p<.001$, and $\left.t_{2}(1,14)=2.18, p<.10\right]$.

These results show that multiple meanings of a word were activated after the participants heard the ambiguous word, because shape competitors attracted a higher proportion of fixations than did filler objects. Even when there was a matching referent to the homophone on the visual display, alternative meanings of a word had an effect on eye movements, directing attention toward the shape competitor of the alternate meaning. Furthermore, relative dominance influenced the duration (and perhaps the degree) of activation of the shape competitors, so that dominant shape competitors were looked at comparatively more than the subordinate shape competitors.

\section{Latency of First Fixation}

The latency of the first look to a critical picture after homophone onset was examined as a function of each homophone's relative dominance in order to evaluate a more detailed correlation between relative meaning dominance and eye movements. Trials that had latencies above three standard deviations were not included, which was $2.6 \%$ of the trials. The average length of the spoken homophone was $527 \mathrm{msec}$, and the amount of time it took to plan and execute an eye movement was approximately $200 \mathrm{msec}$. The mean latency of first looks to the actual referent pictures after homophone onset was $956 \mathrm{msec}$; that is, on average, a fixation to an actual referent was planned within $250 \mathrm{msec}$ of homophone offset. The mean latency of first looks to the shape competitor pictures after homophone onset was $737 \mathrm{msec}$, indicating that many of these fixations were planned prior to homophone offset. The latency to shape competitors may have been shorter than that to actual referents because shape competitors did not require fixations, whereas actual referents were required to be fixated in order to complete the trial as directed. Thus, shape competitors, if fixated at all, were generally not fixated late in the trial. As is shown in Figure 3, meaning dominance inversely affected latency of first look to the actual referent picture: As dominance increased, latency decreased $\left[r(26)=-.52, p<.01 ; F_{2}(1,24)=8.64, p<\right.$ $.01]$. The analogous correlation was not found for shape competitor pictures, suggesting that meaning dominance was more directly related to looking latency for the actual referent than for the shape competitor.

\section{Probability of Fixation}

The proportions of trials on which the participants made at least one look to a shape competitor within $1,000 \mathrm{msec}$ of homophone onset were .42 and .24 for dominant and subordinate shape competitor pictures, respectively. An independent $t$ test confirmed that there were more trials with looks to the dominant shape competitors than with looks to the subordinate shape competitors $\left[t_{1}(1,28)=\right.$

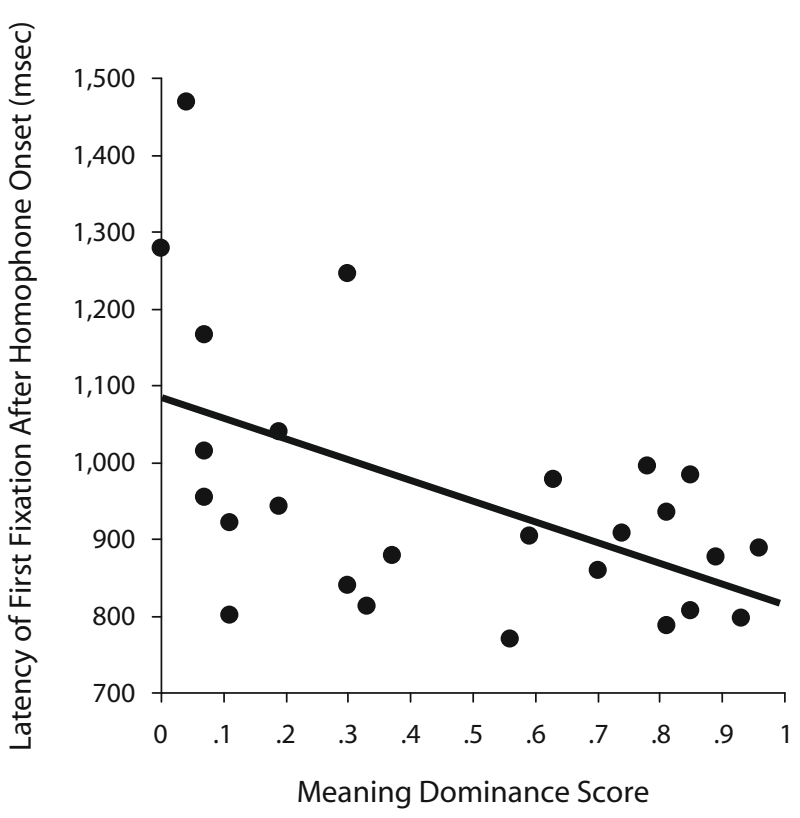

Figure 3. Regression of average latency of first look to the actual referent picture from homophone onset with relative meaning dominance. Shorter latencies were observed for more dominant meanings. 
$\left.3.16, p<.01 ; t_{2}(1,24)=2.46, p<.05\right]$. This was predicted by the relative dominance hypothesis, in which dominant meanings of an ambiguous word are more highly activated than subordinate meanings.

\section{Discussion}

In Experiment 1, as the spoken homophone unfolded in a neutral linguistic context, the participants accessed multiple meanings, and relative activation of the two meanings was measured by observing the proportions of looks to pictures corresponding to each meaning of the homophone. One meaning's activation was measured by looks to a picture depicting an actual referent, and the alternative meaning's activation was measured by looks to a visual shape competitor of that meaning's prototypical referent. Recall that Huettig and Altmann (2007) also found activation of both subordinate and dominant meanings in a neutral context, but it was unclear to what extent the fixation patterns were dependent on visual preview of the potential referents. We find it particularly striking that, in our experiment, the subordinate meaning of the homograph was activated (based on above-chance looks to the shape competitor) even when an actual referent for the dominant meaning was pictured.

The design of our experiment also allowed us to investigate the influence of meaning frequency on fixation patterns. Crucially, we found dominance effects in the proportion of looks to both actual referents and shape competitors. Although neither dominance effect is particularly surprising, given the ubiquity of frequency effects in neutral contexts, it was important to demonstrate that dominance effects could be found with shape competitors when an actual referent was simultaneously pictured. Even though there was a pictured target consistent with the spoken input, activation of other meanings of the homophone directed looks to other objects on the screen - namely, the shape competitors of the alternative meaning.

Because the visual context was presented simultaneously with the spoken homophone, there was no previous visual or linguistic context to bias the meaning of the homophone. Thus, meaning frequency was the only available influence on initial spoken word recognition in this paradigm. Nonetheless, as the visual context was integrated with the spoken input, effects of the visual display on word recognition were observed. That is, initially, looks toward the actual referent and the shape competitor of the alternative meaning of the homophone increased in a similar fashion, but after $700 \mathrm{msec}$, the activation of the alternative meaning decreased, reflecting resolution of the homophone toward the pictured meaning.

\section{EXPERIMENT 2}

Whereas the primary focus in the first experiment was on meaning dominance effects, the primary focus in Experiment 2 was on sentence context effects. The reordered access and selective access accounts of ambiguity resolution differ in how a strong subordinate-biasing context affects the pattern of activation of multiple meanings of homophones, so we manipulated the strength of the subordinate-biasing sentence context before the homophone was heard. The participants heard homophones in either neutral or subordinate-biased contexts (e.g., Neutral, Jenny looked at the table and was surprised to see the flower/flour; Biased, The baker took out the necessary ingredients, like milk, eggs, and flour). At homophone onset, four pictures appeared: a subordinate homophone referent (flour), a dominant meaning shape competitor (lollipop, for flower), and two unrelated pictures. The shape competitor was used to index subliminal activation of the dominant meaning.

Reordered access theories would predict that the dominant meaning of the homophone will still be activated even under a strong subordinate-biasing context, because of the high frequency of the dominant meaning (Duffy et al., 2001; Duffy et al., 1988). This theory would also predict changes in level of activation of the subordinate meaning across context conditions but no change in the initial activation level of the dominant meaning. Although the dominant meaning must eventually be discarded because it is contextually inappropriate, its activation should not be affected by subordinate-biasing contexts. Selective access theories would predict that activation of the dominant meaning is a function of contextual strength, so the dominant meaning should be strongly activated in the neutral context but should not be activated at all in the strongly biased context (Martin et al., 1999).

By comparing both neutral and biasing contexts, we could measure the influence of subordinate-biased context on the activation of both the appropriate and the inappropriate meanings of the homophone. As in Experiment 1, none of the dominant shape competitors overlapped in phonology with the spoken referent names, so any activation of the shape competitor from the spoken input would indicate activation of the dominant meaning of the homophone. The activation of the dominant meaning of the homophone was measured by comparing looks to the shape competitor picture with looks to any of the filler items (by chance). If shape competitors of the dominant homophone meaning attracted more looks than would be expected by chance in the neutral context, the subordinate contexts, or both, multiple meanings have been accessed.

\section{Method}

\section{Participants}

Thirty undergraduates at the University of Michigan participated in this experiment for course credit in an introductory psychology class or were paid for participation. All the participants were native speakers of English and had normal or corrected-to-normal vision.

\section{Materials}

Sixteen homophones were selected with the same criteria as were used in Experiment 1. The 14 homophones from Experiment 1 were included, and 2 additional homophones were added in order to increase statistical power (see Appendix B).

In contrast to Experiment 1, only the subordinate meaning of the homophone was ever pictured as the actual referent, and it always appeared with an object that was similar in shape to one for the dominant meaning of the homophone (shape competitor). The norms used to assess shape similarity will be described below. 
Visual stimuli for each critical trial consisted of four pictures arranged in a $3 \times 3$ grid on a white background with a fixation cross in the center. The critical pictures were all full-color realistic images selected from an online searchable database of images (Google Image Search, 2004). The pictures appeared in the upper left, upper right, lower left, or lower right area of the grid, arranged so that the actual referent appeared in each corner an equal number of times for every participant. The shape competitor also appeared in each corner an equal number of times for every participant. The two remaining corners contained filler pictures of objects with unambiguous names that did not begin with the same phonemes as the critical homophone and were not similar in shape to the critical pictures.

Two linguistic context conditions were created for each of the 16 homophones (see Appendix C). In the subordinate-biased context condition, the participants heard a sentence context that constrained the homophone toward its subordinate meaning (e.g., The baker had agreed to make several pies for a large event today, so he started by taking out necessary ingredients, like milk, eggs, and flour). No lexical associates were used in the sentence, in order to exclude bottomup lexical priming as a factor in activation of either meaning of the homophone. In the neutral context condition, the participants heard a sentence context in which both meanings of the homophone were very plausible (e.g., As Jenny walked into the house after school, she looked at the table and was surprised to see the flower/flour). The norms for meaning bias of sentence contexts appear below. Context condition was varied between participants because the probability of looks to the shape competitor in the subordinate-biased context might be quite low, and we wanted to maximize statistical power for evaluating the hypothesis that the shape competitor was, nonetheless, activated at greater-than-chance levels. Each participant was randomly assigned to one of the two context conditions. The auditory stimuli were recorded by a female speaker.

In addition to the 16 critical homophone trials, 28 filler trials with unambiguous targets were constructed. Trials were presented in a randomized order for each participant.

\section{Norming}

The picture agreement and similarity norms were run again for Experiment 2 in order to incorporate the two items that were not included in Experiment 1. In order to test the contextual strength of the sentences used in Experiment 2, meaning bias norms were also conducted.

Picture agreement norms on shape competitors. In order to ensure that the shape competitor pictures did not activate any lexical items beginning with the same phonemes as the actual homophones, we collected data from a picture-naming agreement task. Twenty-three participants were presented a sequence of 132 pictures on a computer screen. The list was created so that shape competitors of the dominant meaning of the 16 homophone pictures were presented randomly with 116 filler pictures with unambiguous names. Each participant saw every shape competitor once. Only 1 picture appeared on each screen, simultaneously with a box in which the participants were asked to type the name of the picture of the object represented. No responses for the shape competitor pictures indicated any phonological similarity to the actual homophone.

Picture similarity norms. Picture similarity norms indicated that the shape competitors were, in fact, similar in shape to the actual referents. We collected data from a picture similarity task. Twenty-three participants who participated in the picture-naming norms were presented with a series of pictures with questions, such as "How similar in shape is this object to a flower?" The participants were asked to rate, on a scale of 1 (not similar) to 7 (very similar), how similar the presented picture was to the object mentioned in the question. The 16 shape competitor pictures of the dominant homophone meaning were tested according to their similarity to the homophones, along with 58 filler ratings to unrelated objects, which varied in visual form similarity. The shape competitor pictures were presented along with a question asking how similar that object was to the actual homophone object. The participants rated every shape competitor once. The mean rating for shape similarity was 5.25, which indicates high similarity of visual form to the actual dominant homophone referent.

Meaning bias norms. Meaning bias norms indicated that the subordinate-biased sentences indeed biased only the subordinate meaning of the homophone and that the neutral sentences did not favor one meaning of the homophone. We collected data from a sentence bias rating task. Twenty participants were presented with a series of auditory sentences with accompanying questions, such as "Was the sentence you just heard referring to a flower or flour?" The participants were asked to rate, on a scale of 1 (dominant) to 9 (subordinate), the likelihood of two different interpretations of the object mentioned in the sentence. The participants rated every homophone twice, with all 16 neutral sentences rated before the 16 subordinate-biased sentences, dispersed randomly among 40 filler ratings to unrelated sentences. The mean ratings for the subordinate meaning were 8.85 and 4.98 for the subordinate-biased and the neutral sentences, respectively. These bias ratings were converted in the same manner as in Martin et al. (1999) in order to test whether the biased and the neutral distributions overlapped. The scale was converted to represent the strength of deviation from the center of the scale: 0 represented ambiguity, and 4 represented a strong bias. The contexts had the following scores: biased, $M=3.85, S D=0.39$; neutral, $M=-0.02, S D=1.42$. As compared with the strongly biasing contexts in Martin et al., the subordinate-biased contexts were similarly biased or stronger.

Picture saliency norms. Picture saliency norms were conducted to evaluate any difference in saliency among the critical pictures. These norms were collected for all 16 critical trials. The procedure for the saliency norms has been reported above in Experiment 1. Only data from the relevant subordinate actual display will be reported here. The dwell time percentages for each critical picture were the following: actual referents, $21.0 \%$; shape competitors, $18.8 \%$; and filler objects, $18.8 \%$. An independent $t$ test found no advantage in saliency for shape competitors over filler objects $\left(t_{1}<1, t_{2}<1\right)$.

\section{Procedure and Equipment}

Experiment 2 differed from Experiment 1 with regard to the eyetracking system used. Experiment 2 employed an Eyelink II headmounted binocular eyetracking device. As in Experiment 1, the eye cameras were mounted on headgear, but Experiment 2 used a sampling rate of $500 \mathrm{~Hz}$. Also in contrast to Experiment 1, the order of the auditory sentences and their corresponding slides was randomized for each participant.

The participants were seated approximately $24 \mathrm{in}$. from the screen. The distance from the fixation cross to the center of the pictures was approximately $7.5^{\circ}$. The auditory and visual stimuli were presented using SR Research Experiment Builder software. The participants read these instructions:

In this experiment, you will hear a sentence. At the end of the sentence, you will see four objects on the screen. Your task is to click on the object that matches the last word of the sentence you just heard and drag it to the center of the screen. For example, if you heard "The cat was scared of the dog, so it ran under the table," you would click on the TABLE and drag it to the center of the screen. You will also have a comprehension question after every sentence. Please say your answer (YES or NO) out loud.

Before the experiment began, the experimenter performed a calibration procedure. Before each trial, a drift correction procedure was performed. On each trial, the participants looked at a fixation cross while listening to the sentence. The pictures appeared simultaneously at target word onset. The entire experiment lasted less than $30 \mathrm{~min}$.

The data were collected and organized using SR Research Experiment Builder and Data Viewer software.

\section{Results}

The participants responded correctly to the comprehension questions $92.9 \%$ of the time. 
As in Experiment 1, there were two critical pictures on each trial: the actual referent and the shape competitor. The three eye movement measures analyzed included the following: (1) average proportion of looks to critical items from target word onset until 1,000 msec after target onset, (2) first-run dwell time on each of the critical pictures, and (3) visual bias toward shape competitors, measured by $\log$ gaze probability ratios to shape competitor and filler objects from target word onset until 1,000 msec after target onset.

\section{Proportion of Fixations Over Time}

Figure 4 presents the proportions of looks to all four types of critical pictures during each 100 -msec interval after homophone onset, for both context conditions. The effects of context appear to have been quite large, with subordinate-biased context both increasing fixations to the actual referent and decreasing fixations to the shape competitor for the dominant meaning. Clearly, the dominant meaning was strongly activated in the neutral context, as evidenced by many fixations on the shape competitor. Less clear is whether the dominant meaning was still partially activated in the subordinate-biased context.

The proportion of looks to critical objects seems to have risen more slowly in Experiment $1(500 \mathrm{msec})$ than in Experiment 2 (300 msec). Several factors may have contributed to this difference in timing, and it is most likely that a combination of factors caused these differences. First, differences in the display types between the two experiments can explain some of the timing difference. In Experiment 1, the pictured objects were located in one of the four large quadrants of the screen, but varied in size and location within the quadrants. In contrast, in Experiment 2, a $3 \times 3$ grid in the center of the screen was used on every trial, with a picture in each corner of the grid. The size of each picture was adjusted to be as large as possible, while still fitting within the boundaries of the appropriate square. Thus, the locations and sizes of the objects were more constrained in Experiment 2, whereas the pictures tended to be larger, more irregular, and farther from the fixation cross in Experiment 1. We think that this difference in the visual layout of the screen may have made it easier in Experiment 2 to quickly assess the content of each picture and to plan a saccade to the appropriate picture. Second, the more constraining sentence contexts in Experiment 2 may have contributed to differences in time course. Even the neutral sentences in Experiment 2 semantically constrained the interpretation of the homophone prior to homophone onset, as compared with the unvarying spoken instructions in Experiment 1. This may have led to shorter lexical access times, which, in turn, would lead to earlier fixations on the pictures. (In contrast, in both experiments, predictive processing due to the visual display was not likely, because the pictures did not appear until homophone onset.) Lastly, differences in tasks, instructions, and equipment between the two experiments may have also played a role. In particular, Experiment 1 employed a pointing task, whereas Experiment 2 required the participants to use the computer mouse, which may have made the participants more tuned to the mouse pointer and other objects on the screen.

To evaluate the time course of the influence of biasing context, we analyzed the proportion of looks to each critical picture in 100-msec intervals from target word onset. First, we contrasted looks to the actual referent during subordinate-biased and neutral contexts, using independent $t$ tests. Starting at $300 \mathrm{msec}$, the subordinate-biased context increased looks to the actual referents, as compared with the neutral context, by participants $[300 \mathrm{msec}$, $\left.t_{1}(1,28)=2.97, p<.01 ; t_{2}(1,30)=1.83, p<.10\right]$.

The context also influenced the probability of looks to the shape competitors. Starting at $500 \mathrm{msec}$, there were fewer fixations to the shape competitor in the subordinatebiased context than in the neutral context by participants,

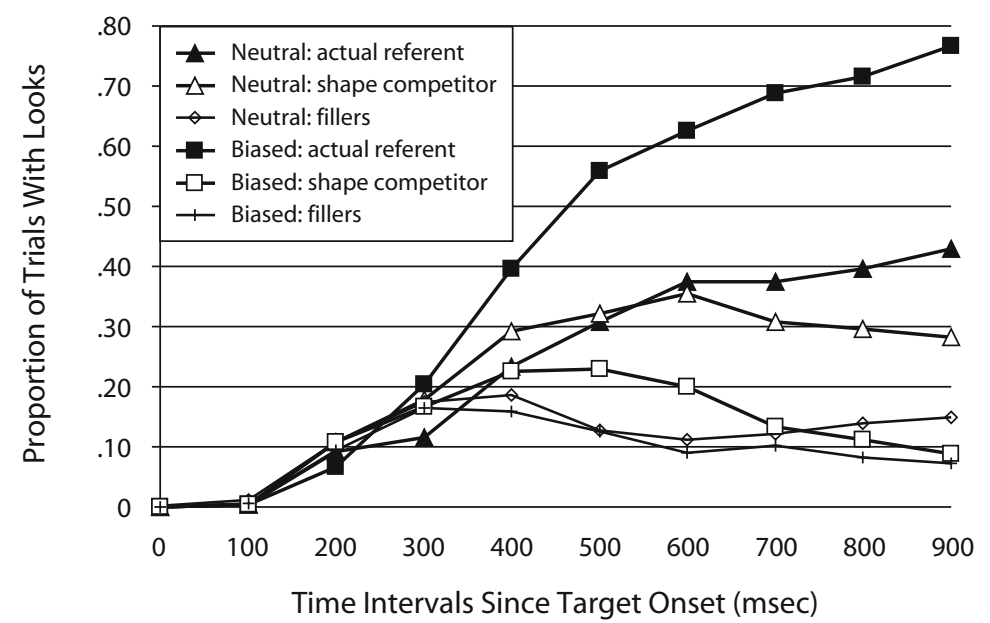

Figure 4. All the data from both contextual bias conditions are summarized here. For each contextual bias condition, we show the proportions of trials within a 100-msec interval with fixations on the actual referent, the shape competitor, or the average of the filler objects. The first time interval is $0-99$ msec after homophone onset. 
and at $600 \mathrm{msec}$, there were fewer both by participants and by items $\left[500 \mathrm{msec}, t_{1}(1,28)=-2.56, p<.05\right.$, and $t_{2}(1,30)=-1.43, p>.10 ; 600 \mathrm{msec}, t_{1}(1,28)=-4.34$, $p<.001$, and $\left.t_{2}(1,30)=-2.20, p<.05\right]$. Together, these findings indicate that at early time intervals, the subordinate-biased context both increased activation of the subordinate meaning and decreased activation of the dominant meaning, relative to a neutral context.

\section{First-Run Dwell Time}

First-run dwell time was analyzed in order to evaluate initial processing time for each of the fixated objects. The mean first-run dwell times (in milliseconds) for the critical objects in the neutral context condition (with standard errors) were as follows: actual referent, 590 (13); shape competitor, 246 (6); filler objects, 205 (3). The means for the subordinate-biased context condition were as follows: actual referent, 706 (15); shape competitor, 228 (9); filler objects, 192 (3).

In order to determine whether the dominant meaning of the homophone was activated at above-chance levels, firstrun dwell times for the shape competitors were compared with mean first-run dwell times for the unrelated filler objects. For each contextual bias condition, independent $t$ tests were performed. In the neutral context condition, shape competitors had longer first-run dwell times than did fillers, as was expected $\left[t_{1}(43)=6.26, p<.001 ; t_{2}(46)=\right.$ $6.49, p<.001]$. Interestingly, this effect also occurred in the subordinate-biased context condition: Shape competitors had longer first-run dwell times than did filler objects $\left[t_{1}(43)=5.29, p<.001 ; t_{2}(46)=2.93, p<.01\right]$. These findings suggest that the dominant meaning, represented by the shape competitor, was activated at levels higher than chance, even in the subordinate-biased context.

Contextual bias effects on the first-run dwell times to actual referents and shape competitors were analyzed using $t$ tests. There was an effect of context type on actual referents $\left[t_{1}(28)=3.20, p<.01 ; t_{2}(30)=4.14, p<.001\right]$, so that the actual referent in the subordinate-biased con- text condition was fixated longer than that in the neutral context. This effect confirms that the subordinate-biasing context boosted activation of the subordinate meaning. There was, however, no context effect on shape competitors $\left[t_{1}(28)=1.10, p>.10 ; t_{2}(30)=1.66, p>.10\right]$.

\section{Visual Bias of Shape Competitors}

As another test of whether the dominant homophone meaning was activated in the subordinate-biased context, we compared the observed proportion of looks with the proportion that would be expected on the basis of chance alone. To evaluate this activation, we used log gaze ratios as a measure of visual bias to the shape competitors, as compared with the filler objects. Log gaze ratios provide a measure of bias toward the dominant meaning, as compared with filler objects, that is independent from the level of activation of the subordinate meaning. If shape competitors are activated more than filler objects, this would be evidence for higher activation than would be expected by chance. Figure 5 plots the time course of log gaze ratios for each context condition. Due to missing values, statistics could be computed starting only from the 200-msec interval.

One-way ANOVAS compared the log gaze ratios with 0 across participants and items for each 100 -msec interval from $200 \mathrm{msec}$ to $1,000 \mathrm{msec}$ after target onset. In the neutral context, there was a visual bias toward shape competitors, as compared with filler objects, starting at $400 \mathrm{msec}$, significant only by participants, not by items $\left[F_{1}(1,26)=\right.$ $\left.16.17, p<.001 ; F_{2}(1,30)=3.23, p<.10\right]$, and continuing from 500 to $1,000 \mathrm{msec}$ by both participants and items [500 msec, $F_{1}(1,26)=40.26, p<.001$, and $F_{2}(1,30)=14.24, p<.01 ; 600 \mathrm{msec}, F_{1}(1,26)=50.45$, $p<.001$, and $F_{2}(1,26)=38.15, p<.001 ; 700 \mathrm{msec}$, $F_{1}(1,26)=23.79, p<.001$, and $F_{2}(1,28)=8.48, p<$ $.01 ; 800 \mathrm{msec}, F_{1}(1,24)=10.82, p<.01$, and $F_{2}(1,28)=$ $24.80, p<.001 ; 900 \mathrm{msec}, F_{1}(1,24)=5.57, p<.05$, and $\left.F_{2}(1,30)=17.18, p<.001\right]$. More important, in the subordinate-biased context, there was still a visual bias toward the shape competitors, as compared with the filler

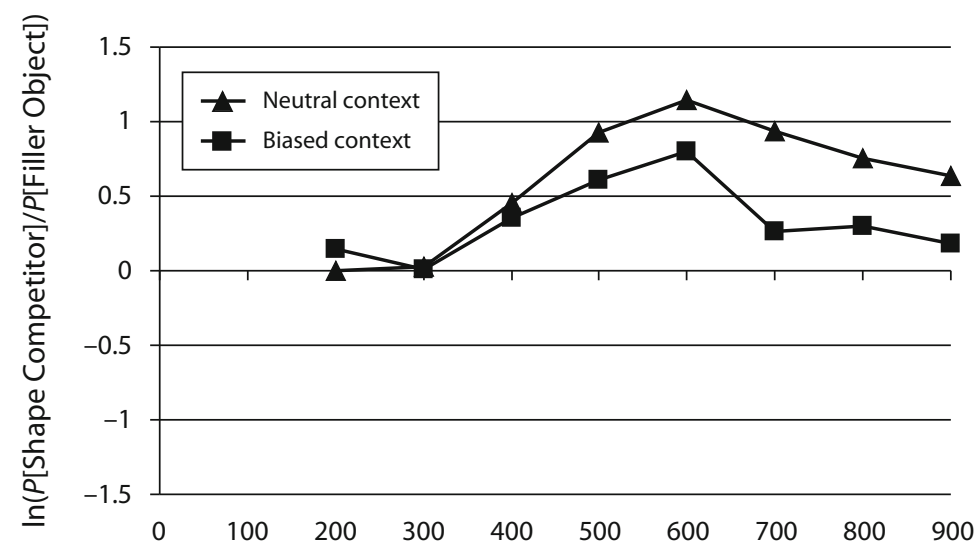

Time Intervals From Target Onset (msec)

Figure 5. Average log gaze ratios for each context condition in 100-msec time intervals. The first time interval is $\mathbf{0}-\mathbf{9 9} \mathbf{m s e c}$ after homophone onset. 
objects, that was significant at $400 \mathrm{msec}$ by participants $\left[F_{1}(1,28)=11.11, p<.01 ; F_{2}(1,26)=3.13, p<.10\right]$ and by both participants and items at 500 and $600 \mathrm{msec}$ $\left[500 \mathrm{msec}, F_{1}(1,28)=15.14, p<.01\right.$, and $F_{2}(1,26)=$ $4.34, p<.05 ; 600 \mathrm{msec}, F_{1}(1,26)=17.78, p<.001$, and $\left.F_{2}(1,26)=5.11, p<.05\right]$. Dominant meaning activation is predicted by all theories in the neutral context; however, evidence of dominant meaning activation during the strong subordinate-biased context was predicted only by the reordered access theory.

To determine whether the subordinate-biased context affected the level of activation of the dominant meaning, as represented by the shape competitor, the log ratio of bias toward the dominant shape competitor was compared across context conditions for each $100-\mathrm{msec}$ interval. At $600 \mathrm{msec}$ after homophone onset, one-tailed $t$ tests revealed a larger bias in the neutral than in the subordinatebiasing context $\left[t_{1}(1,26)=1.84, p<.05 ; t_{2}(1,18)=1.97\right.$, $p<.05] .{ }^{1}$ Assuming that this effect reflects early lexical processing, and not postlexical processing, this difference indicates that context did influence the activation level of the dominant meaning. This finding is problematic for a strict version of reordered access that assumes that a subordinate-biased context has an effect only on the subordinate meaning, by increasing its initial activation, and leaves the dominant meaning activation unaffected. This finding, however, is consistent with the selective access view that a strong subordinate-biasing context both increases activation of the subordinate meaning and limits activation of the dominant meaning.

\section{Discussion}

Three important findings are reported here. First, context influenced the proportion of fixations on the subordinate actual referent, starting at $300 \mathrm{msec}$ after homophone onset. This finding is consistent with all accounts of the subordinate bias effect, as well as both reordered and selective access accounts. Second, the dominant shape competitor attracted more fixations than would be expected by chance, even in the subordinate-biased context condition. This effect is predicted by competition-based accounts of the subordinate bias effect and by the reordered access account and is consistent with the Huettig and Altmann (2007) findings, but it is not consistent with selective access accounts.

Third, context influenced the proportion of fixations on the dominant shape competitor, beginning $500 \mathrm{msec}$ after homophone onset, according to the raw proportion of fixations over time. Using a more stringent test (log ratios), context influenced the amount of bias toward the dominant shape competitor, beginning $600 \mathrm{msec}$ after homophone onset. The theoretical importance of this finding depends on whether it reflects contextual modulation over initial access of the dominant meaning, as would be expected under selective access, or rapid use of context to select the appropriate meaning, as would be expected under reordered access. Average homophone duration was $527 \mathrm{msec}$, and the amount of time it took to plan and execute an eye movement was approximately $200 \mathrm{msec}$, so the linguistic context began to influence looks to the pictured objects prior to homophone offset. Of course, spoken word recognition can occur midword in some cases (Marslen-Wilson, 1975; Marslen-Wilson \& Tyler, 1975), so the fact that our context effects begin prior to homophone offset is no guarantee that they reflect initial lexical access, rather than postaccess processes.

One factor that seems to support the reordered access account is that the context effects emerged about $200 \mathrm{msec}$ earlier for the contextually supported subordinate actual referent than they did for the contextually unsupported dominant shape competitor. The reordered access account maintains that, in a subordinate-biased context as compared with a neutral context, access to the subordinate meaning will be faster. Initial access to the dominant meaning will be unaffected, but once context is used to select the subordinate meaning, the dominant meaning will become less activated. In our experiment, if looks to the actual referent and the shape competitor were equally sensitive to activation of the subordinate and dominant meanings, respectively, a different time course for context effects would indeed be predicted by the reordered access account. Unfortunately, because only the subordinate meaning was actually pictured, whereas the dominant meaning was represented by a shape competitor, the implications of this time course difference are unclear. It is also unclear whether the later context effects for the shape competitor were actually late enough to reflect postaccess processing.

Another way to gauge the theoretical implications of the contextual modulation of the dominant meaning in our experiment is to compare the time course of our results with that in well-known cross-modal priming studies. (It is more difficult to compare the time course of our results with those in reading studies, because the perception of word form and the temporal dynamics of lexical activation are quite different in the written and spoken modalities.) The classic experiments that initially established multiple meaning activation presented the target word at homophone offset (Swinney, 1979; Tanenhaus et al., 1979). To the extent that the paradigms are comparable, our experiments tapped lexical processing at a slightly earlier time point than did those experiments, and certainly earlier than cross-modal experiments that delayed presentation of the target word until $200 \mathrm{msec}$ or more after homophone offset, demonstrating that, by that time, a single referent had been selected after initially activating multiple candidates (e.g., Seidenberg, Tanenhaus, Leiman, \& Bienkowski, 1982).

Another point of comparison is provided by the more recent visual world experiments investigating lexical activation. For example, Allopenna, Magnuson, and Tanenhaus (1998) found more fixations to unambiguous referents and phonological cohorts than to controls from 300 to $700 \mathrm{msec}$ after the critical word. Similarly, Dahan et al. (2001) found more fixations to unambiguous referents and phonological cohorts than to controls from 200 to $500 \mathrm{msec}$ after the critical word. These effects occurred before the offset of the spoken target, with eye movements planned almost immediately after target onset. However, in both cases, the spoken input was disambiguated earlier 
than in our present experiments, which could affect how early the saccades were planned. Also, the pictures were on the screen for several seconds prior to pronunciation of the critical word, which could conceivably allow strategic processing of the visual input, increasing lexical activation prior to integration of the spoken input. At a minimum, free viewing of the pictures before the target word was heard would facilitate saccade planning.

In sum, we cannot completely rule out the possibility that the context effects on the dominant meaning reflect postaccess use of context, but taken together with the broader literature, it is most likely that the context modulated the initial activation of the dominant meaning. If so, these findings provide evidence against any theory of lexical ambiguity resolution that maintains that the dominant meaning is always accessed simply on the basis of the strong form-meaning mapping and is not modulated by sentential context. Thus, a strict version of reordered access in which only activation of the contextually appropriate meaning is influenced by context cannot provide an account of this finding.

In short, our data support a version of reordered access in which the activation of each of a homophone's meanings is modulated by context very early during lexical access. A strong subordinate bias may both increase the activation of the subordinate meaning and decrease activation of the dominant meaning. For balanced homophones, context may sometimes be strong enough to selectively activate a single meaning. However, for polarized homophones, the dominant meaning is likely to be somewhat activated, even in strongly subordinate-biased contexts, solely on the basis of the strength of its form-meaning mapping. Although context can have a great influence on activation of each of the homophone meanings, activation of a strongly dominant meaning probably cannot be completely overridden. This account is similar to the reordered access account of Duffy et al. (2001; Duffy et al., 1988).

\section{GENERAL DISCUSSION}

In Experiment 1, using neutral imperative sentence contexts, both the pictured referent meaning of the homophone and the alternative shape competitor meaning of the homophone competed for attention following the spoken homophone. Importantly, we found dominance effects on looks to shape competitors when an actual referent was simultaneously pictured. Dominant meanings were activated more strongly than subordinate meanings, as is shown by the high number of looks to the dominant shape competitors. Second, although subordinate meaning shape competitors received fewer overall looks than did dominant meaning shape competitors, they nonetheless received above-chance attention, despite the presence of an actual referent for the dominant meaning. Both effects are somewhat surprising, given that shape competitors had no connection to the spoken homophone, except that they were visual competitors of the alternate meaning. As such, our results add to the growing body of shape competitor findings in the visual world paradigm indicating that shape competitors provide an unobtrusive but sensitive index of lexical activation (Dahan \& Tanenhaus, 2005; Huettig \& Altmann, 2007; Huettig et al., 2004).

In Experiment 2, we demonstrated that top-down processing from sentential context can influence the pattern of activation of multiple meanings of a homophone, so that subordinate-biasing context boosts activation of the subordinate meaning of the homophone. More important, analyses of looks to shape competitors designating the dominant meaning of the homophone revealed that the subordinate-biasing context decreased activation of the dominant meaning, although the dominant meaning was still activated more than would be expected by chance. This provides evidence that multiple access of homophone meanings still occurs, even when the biasing sentential and visual context allows only one interpretation of the homophone, which is consistent with the results of Huettig and Altmann (2007), previous reading studies showing the subordinate bias effect even during strongly biased contexts, and the reordered access account (Binder, 2003; Binder \& Rayner, 1998; Kambe et al., 2001; Pacht \& Rayner, 1993; Rayner et al., 2006; Rayner et al., 1994, Sereno et al., 2006; Sereno et al., 1992). Multiple access, however, is inconsistent with the predictions of selective access models, where the subordinate bias effect should be eliminated in strongly biasing subordinate contexts. As was discussed above, both our normative data and the large, immediate effects of contextual bias suggest that our subordinate-biased contexts were indeed strongly biasing.

In contrast, the finding that the subordinate-biasing context decreases activation of the dominant meaning is not consistent with a strict version of reordered access that assumes that contextually inappropriate meanings are not influenced by disambiguating context (Duffy et al., 2001; Duffy et al., 1988). This finding is, however, consistent with selective access accounts, where frequency, type of context, and strength of context can influence homophone meaning activation (Martin et al., 1999). Neither a strict version of reordered access nor selective access is capable of accounting for all our findings in the present study. A more appropriate approach may be a version of reordered access in which both frequency and strength of context can constrain activation of each homophone meaning, but neither factor is able to completely dominate patterns of lexical activation.

\section{AUTHOR NOTE}

Correspondence concerning this article should be addressed to L. Chen, Department of Psychology, University of Michigan, 530 Church Street, Ann Arbor, MI 48109-1043 (e-mail: 1illianc@umich.edu).

\section{REFERENCES}

Allopenna, P. D., Magnuson, J. S., \& Tanenhaus, M. K. (1998). Tracking the time course of spoken word recognition using eye movements: Evidence for continuous mapping models. Journal of Memory \& Language, 38, 419-439.

Arai M., Van Gompel, R. P. G., \& Scheepers, C. (2007). Priming ditransitive structures in comprehension. Cognitive Psychology, 54, 218-250.

BINDER, K. S. (2003). Sentential and discourse topic effects on lexical ambiguity processing: An eye-movement examination. Memory \& Cognition, 31, 690-702. 
Binder, K. S., \& RAYNER, K. (1998). Contextual strength does not modulate the subordinate bias effect: Evidence from eye fixations and selfpaced reading. Psychonomic Bulletin \& Review, 5, 271-276.

Dahan, D., Magnuson, J. S., \& Tanenhaus, M. K. (2001). Time course of frequency effects in spoken-word recognition: Evidence from eye movements. Cognitive Psychology, 42, 317-367.

Dahan, D., \& Tanenhaus, M. K. (2005). Looking at the rope when looking for the snake: Conceptually mediated eye movements during spoken-word recognition. Psychonomic Bulletin \& Review, 12, 453-459.

Dopkins, S., Morris, R. K., \& RAYner, K. (1992). Lexical ambiguity and eye fixations in reading: A test of competing models of lexical ambiguity resolution. Journal of Memory \& Language, 31, 461-477.

Duffy, S. A., Kambe, G., \& Rayner, K. (2001). The effect of prior disambiguating context on the comprehension of ambiguous words: Evidence from eye movements. In D. S. Gorfein (Ed.), On the consequences of meaning selection: Perspectives on resolving lexical ambiguity (pp. 27-43). Washington, DC: American Psychological Association.

Duffy, S. A., Morris, R., \& RAYner, K. (1988). Lexical ambiguity and fixation times in reading. Journal of Memory \& Language, 27, 429-446.

Google Image Search (2004). Retrieved January 2004, from images .google.com.

Huettig, F., \& Altmann, G. T. M. (2007). Visual-shape competition during language-mediated attention is based on lexical input and not modulated by contextual appropriateness. Visual Cognition, 15, 985-1018.

Huettig, F., Gaskell, M. G., \& Quinlan, P. T. (2004). How speech processing affects our attention to visually similar objects: Shape competitor effects and the visual world paradigm. In K. Forbus, D. Gentner, \& T. Regler (Eds.), Proceedings of the 26th Annual Meeting of the Cognitive Science Society (pp. 607-612). Mahwah, NJ: Erlbaum.

Kambe, G., Rayner, K., \& Duffy, S. A. (2001). Global context effects on processing lexically ambiguous words: Evidence from eye fixations. Memory \& Cognition, 29, 363-372.

Kellas, G., Martin, C., Yehling, K., Herman, R., \& Vu, H. (1995). Contextual strength as a determinant of the subordinate bias effect. Poster presented at the 36th Annual Meeting of the Psychonomic Society, Los Angeles.

Kellas, G., \& Vu, H. (1999). Strength of context does modulate the subordinate bias effect: A reply to Binder and Rayner. Psychonomic Bulletin \& Review, 6, 511-517.

LuCAs, M. (1999). Context effects in lexical access: A meta-analysis. Memory \& Cognition, 27, 385-398.

Marslen-Wilson, W. D. (1975). Sentence perception as an interactive parallel process. Science, 189, 226-228.

Marslen-Wilson, W. D., \& Tyler, L. K. (1975). Processing structure of sentence perception. Nature, 257, 784-786.

Martin, C., Vu., H., Kellas, G., \& Metcalf, K. (1999). Strength of discourse contexts as a determinant of the subordinate bias effect. Quarterly Journal of Experimental Psychology, 52A, 813-839.

ONIFER, W., \& SWINNEY, D. A. (1981). Accessing lexical ambiguities during sentence comprehension: Effects of frequency of meaning and contextual bias. Memory \& Cognition, 9, 225-236.

Pacht, J. M., \& Rayner, K. (1993). The processing of homophonic homographs during reading: Evidence from eye movement studies. Journal of Psycholinguistic Research, 22, 251-271.

RAYNer, K., Binder, K. S., \& DufFy, S. A. (1999). Contextual strength and the subordinate bias effect: Comment on Martin, Vu, Kellas, and Metcalf. Quarterly Journal of Experimental Psychology, 52A, 841-852.

Rayner, K., CoOK, A. E., Juhasz, B. J., \& Frazier, L. (2006). Immediate disambiguation of lexically ambiguous words during reading: Evidence from eye movements. British Journal of Psychology, 97, 467-482.

Rayner, K., PaCht, J. M., \& Duffy, S. A. (1994). Effects of prior encounter and global discourse bias on the processing of lexically ambiguous words: Evidence from eye fixations. Journal of Memory \& Language, 33, 527-544.

Reichle, E. D., Pollatsek, A., \& Rayner, K. (2007). Modeling the effects of lexical ambiguity on eye movements during reading. In R. P. G. Van Gompel, M. H. Fischer, W. S. Murray, \& R. L. Hill
(Eds.), Eye movements: A window on mind and brain (pp. 271-292). Amsterdam: Elsevier.

Reichle, E. D., Rayner, K., \& Pollatsek, A. (2003). The E-Z Reader model of eye movement control in reading: Comparisons to other models. Behavioral \& Brain Sciences, 26, 445-476.

Seidenberg, M. S., Tanenhaus, M. J., Leiman, J. M., \& BienKOWSKI, M. (1982). Automatic access of the meanings of ambiguous words in context: Some limitations of knowledge-based processing. Cognitive Psychology, 14, 538-559.

Sereno, S. C., Brewer, C. C., \& O'Donnell, P. J. (2003). Context effects in word recognition: Evidence for early interactive processing. Psychological Science, 14, 328-333.

Sereno, S. C., O'Donnell, P. J., \& Rayner, K. (2006). Eye movements and lexical ambiguity resolution: Investigating the subordinatebias effect. Journal of Experimental Psychology: Human Perception \& Performance, 32, 335-350.

Sereno, S. C., Pacht, J. M., \& Rayner, K. (1992). The effect of meaning frequency on processing lexically ambiguous words: Evidence from eye fixations. Psychological Science, 3, 296-300.

Simpson, G. B. (1981). Meaning dominance and semantic context in the processing of lexical ambiguity. Journal of Verbal Learning \& Verbal Behavior, 20, 120-136.

Simpson, G. B., \& Burgess, C. (1985). Activation and selection processes in the recognition of ambiguous words. Journal of Experimental Psychology: Human Perception \& Performance, 11, 28-39.

Simpson, G. B., \& KRUEGER, M. (1991). Selective access of homograph meanings in sentence context. Journal of Memory \& Language, 30, 627-643.

SWINNEY, D. A. (1979). Lexical access during sentence comprehension: (Re)consideration of context effects. Journal of Verbal Learning \& Verbal Behavior, 18, 645-659.

TABossi, P. (1988). Accessing lexical ambiguity in different types of sentential contexts. Journal of Memory \& Language, 27, 324-340.

TAвossi, P. (1993). Processing ambiguous words in context. Journal of Memory \& Language, 32, 359-372.

Taвossi, P., Colombo, L., \& Job, R. (1987). Accessing lexical ambiguity: Effects of context and dominance. Psychological Research, 49, 161-167.

Tanenhaus, M. K., Leiman, J. M., \& Seidenberg, M. S. (1979). Evidence for multiple stages in the processing of ambiguous words in syntactic contexts. Journal of Verbal Learning \& Verbal Behavior, 18, 427-440.

Tanenhaus, M. K., Spivey-Knowlton, M., Eberhard, K., \& SeDIVY, J. (1995). Integration of visual and linguistic information during spoken language comprehension. Science, 268, 1632-1634.

Vu, H., \& Kellas, G. (1999). Contextual strength modulates the subordinate bias effect: Reply to Rayner, Binder, and Duffy. Quarterly Journal of Experimental Psychology, 52A, 853-855.

Vu, H., Kellas, G., Metcalf, K., \& Herman, R. (2000). The influence of global discourse on lexical ambiguity resolution. Memory \& Cognition, 28, 236-252.

Vu, H., Kellas, G., \& Paul, S. T. (1998). Sources of sentence constraint on lexical ambiguity resolution. Memory \& Cognition, 26, 979-1001.

Vu, H., Kellas, G., Petersen, E., \& Metcalf, K. (2003). Situationevoking stimuli, domain of reference, and the incremental interpretation of lexical ambiguity. Memory \& Cognition, 31, 1302-1315.

WiLEY, J., \& RAYNER, K. (2000). Effects of titles on the processing of text and lexically ambiguous words: Evidence from eye movements. Memory \& Cognition, 28, 1011-1021.

\section{NOTE}

1. A one-tailed $t$ test is appropriate here because subordinate-biasing context is predicted to decrease activation of the dominant meaning, according to selective access, whereas reordered access predicts no effect of context on the dominant meaning. A more conservative two-tailed test revealed a marginal context effect on the dominant meaning, by both participants and items $\left[t_{1}(1,26)=1.84, p<.10 ; t_{2}(1,18)=1.97, p<.10\right]$. However, the two-tailed $t$ test was fully significant when we excluded the three items whose subordinate-biased and neutral contexts differed by less than $30 \%$ in the meaning bias norms of Experiment $2\left[t_{1}(1,25)=\right.$ $\left.2.55, p<.05 ; t_{2}(1,18)=3.13, p<.01\right]$. 
APPENDIXA

Critical Stimuli for Experiment 1

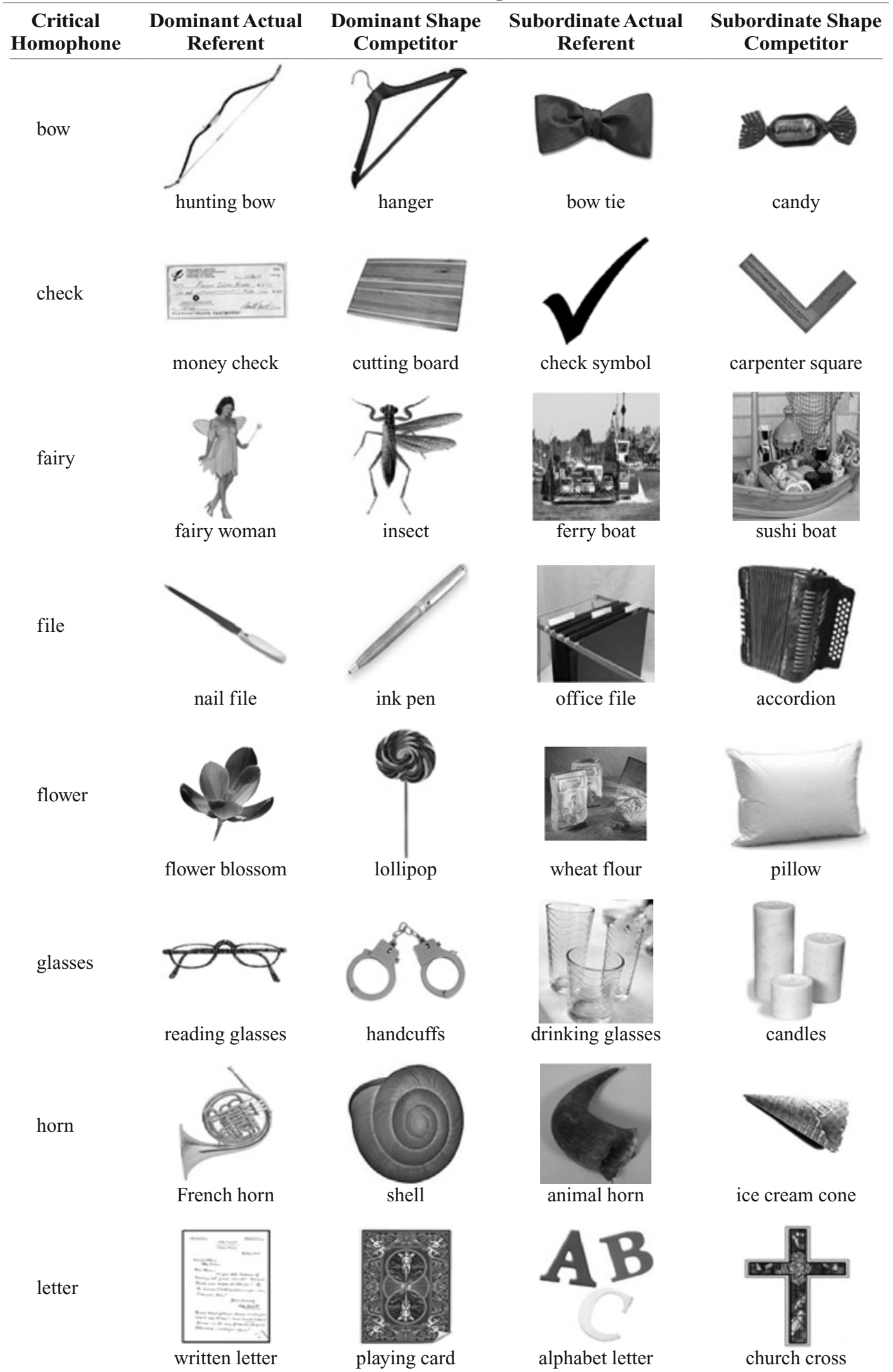




\begin{tabular}{|c|c|c|c|c|}
\hline $\begin{array}{c}\text { Critical } \\
\text { Homophone }\end{array}$ & $\begin{array}{c}\text { Dominant Actual } \\
\text { Referent }\end{array}$ & $\begin{array}{l}\text { Dominant Shape } \\
\text { Competitor }\end{array}$ & $\begin{array}{c}\text { Subordinate Actual } \\
\text { Referent }\end{array}$ & $\begin{array}{l}\text { Subordinate Shape } \\
\text { Competitor }\end{array}$ \\
\hline \multicolumn{5}{|l|}{ nails } \\
\hline \multirow{3}{*}{ note } & hand nails & lipstick & hammer nails & pencils \\
\hline & & & & \\
\hline & written note & framed painting & music note & ladle \\
\hline nut & nut in shell & brain & tool nut & hexagonal boxes \\
\hline \multicolumn{5}{|l|}{ ring } \\
\hline & wedding ring & inner tube & boxing ring & sandbox \\
\hline \multicolumn{5}{|l|}{ stamp } \\
\hline & letter stamp & painting & ink stamp & joystick \\
\hline $\operatorname{tank}$ & army tank & slide projector & water tank & pill \\
\hline
\end{tabular}


APPENDIX B

Additional Stimuli for Experiment 2

\begin{tabular}{cccc}
$\begin{array}{c}\text { Critical } \\
\text { Homophone }\end{array}$ & $\begin{array}{c}\text { Dominant Actual } \\
\text { Referent }\end{array}$ & $\begin{array}{c}\text { Dominant Shape } \\
\text { Competitor }\end{array}$ & $\begin{array}{c}\text { Subordinate } \\
\text { Actual Referent }\end{array}$ \\
hose & watering hose & snake & digging hoes \\
trunk & & present & elephant trunk \\
\hline
\end{tabular}

APPENDIX C

Sentence Stimuli for Experiment 2

\begin{tabular}{|c|c|c|}
\hline Item & Condition & Sentence \\
\hline Bow & biased & $\begin{array}{l}\text { When the girls at the slumber party decided to play dress-up, Katie put make-up on } \\
\text { Monica, and Jessica put up Lisa's hair with a bow. }\end{array}$ \\
\hline Bow & neutral & $\begin{array}{l}\text { There was a blackout tonight, so there was no chance that Jamie would be able to find } \\
\text { the bow. }\end{array}$ \\
\hline Check & biased & $\begin{array}{l}\text { Normally, Alice gets A plusses on her papers, but today she found out that the teacher } \\
\text { marked it only with a check. }\end{array}$ \\
\hline Check & neutral & $\begin{array}{l}\text { Mr. White was working on the case all morning and did not realize that on the front } \\
\text { page there was a check. }\end{array}$ \\
\hline Ferry & biased & $\begin{array}{l}\text { The travelers could not bring their car to the island because they didn't have enough } \\
\text { cash to pay for their car to be loaded onto the ferry. }\end{array}$ \\
\hline Ferry & neutral & $\begin{array}{l}\text { During last Tuesday's art class, Lee's teacher was impressed by his detailed drawing of } \\
\text { a ferry. }\end{array}$ \\
\hline File & biased & $\begin{array}{l}\text { At the end of the work day, the manicurist cleaned up the salon and put everything } \\
\text { back in its place, the cotton swabs, the polish, and the file. }\end{array}$ \\
\hline File & neutral & $\begin{array}{l}\text { Andrea wondered how her sister ever got any work done, because she did not do any- } \\
\text { thing except sit and occupy herself with a file. }\end{array}$ \\
\hline Flour & biased & $\begin{array}{l}\text { The baker had agreed to make several pies for large event today, so he started by tak- } \\
\text { ing out necessary ingredients, like milk, eggs, and flour. }\end{array}$ \\
\hline Flour & neutral & $\begin{array}{l}\text { As Jenny walked into the house after school, she looked at the table and was surprised } \\
\text { to see the flour. }\end{array}$ \\
\hline Glasses & biased & $\begin{array}{l}\text { The restaurant's dishwashers had a scheme that worked very efficiently: first they } \\
\text { would wash the plates, then the silverware, and finally the glasses. }\end{array}$ \\
\hline Glasses & neutral & $\begin{array}{l}\text { Amanda was on the phone and wasn't able to supervise her little brother, who ended } \\
\text { up dropping the glasses. }\end{array}$ \\
\hline Hoes & biased & $\begin{array}{l}\text { Kim wanted to plant daisies in the yard, so she asked the boys to start preparing the } \\
\text { soil with the hoes. }\end{array}$ \\
\hline Hoes & neutral & $\begin{array}{l}\text { It was spring cleaning time, and George always had a hard time throwing old items } \\
\text { away, like the hoes. }\end{array}$ \\
\hline Horn & biased & $\begin{array}{l}\text { The environmentalist was especially protective of a specific species of rhinoceros that } \\
\text { people often kill for its horn. }\end{array}$ \\
\hline Horn & neutral & $\begin{array}{l}\text { Charlie was looking through his closet for a set of screwdrivers, but ended up only } \\
\text { finding a horn. }\end{array}$ \\
\hline Letter & biased & $\begin{array}{l}\text { The kindergartener was usually good at writing her name on the chalkboard, but today } \\
\text { she mistakenly added an extra letter. }\end{array}$ \\
\hline Letter & neutral & $\begin{array}{l}\text { In lecture this morning, Daniel heard that a lot of confusions can occur just because of } \\
\text { one letter. }\end{array}$ \\
\hline Nails & biased & $\begin{array}{l}\text { The father was about to fix the door on the shed, and remembered to bring a wrench } \\
\text { but forgot to bring nails. }\end{array}$ \\
\hline Nails & neutral & $\begin{array}{l}\text { The homeowner was trying to fix her porch, but she was annoyed to find some dirt on } \\
\text { her nails. }\end{array}$ \\
\hline
\end{tabular}


APPENDIX C (Continued)

\begin{tabular}{|c|c|c|}
\hline Item & Condition & Sentence \\
\hline Note & biased & $\begin{array}{l}\text { The pianist had had the opportunity to study the sheet music carefully, but when play- } \\
\text { ing the piece she still missed one note. }\end{array}$ \\
\hline Note & neutral & $\begin{array}{l}\text { The director believed Julie's story that she had been so absent-minded in class that she } \\
\text { didn't see the note. }\end{array}$ \\
\hline Nut & biased & $\begin{array}{l}\text { The builder was very organized with his tools, so he knew exactly which compartment } \\
\text { in his toolbox contained the right nut. }\end{array}$ \\
\hline Nut & neutral & $\begin{array}{l}\text { Trevor felt something funny in his pocket, so he stood up, put his hand in his pocket, } \\
\text { and found a nut. }\end{array}$ \\
\hline Ring & biased & $\begin{array}{l}\text { The wrestler was nervous about the next fight, so he meditated a bit before climbing } \\
\text { into the ring. }\end{array}$ \\
\hline Ring & neutral & $\begin{array}{l}\text { Morgan worked for a magazine and was delighted to accept the assignment to photo- } \\
\text { graph the ring. }\end{array}$ \\
\hline Stamp & biased & $\begin{array}{l}\text { The woman wanted to make a personalized greeting card for her nephew, so she took } \\
\text { out her ink pad and created a design using a stamp. }\end{array}$ \\
\hline Stamp & neutral & $\begin{array}{l}\text { Allison was in a rush on Tuesday, and her desk was so messy that she did not find the } \\
\text { stamp. }\end{array}$ \\
\hline Tank & biased & $\begin{array}{l}\text { The company needed to store a large amount of liquid in their facilities, so they decide } \\
\text { to install an above-ground tank. }\end{array}$ \\
\hline Tank & neutral & $\begin{array}{l}\text { It was hard to see through the fog, but it was easy to notice that the object in the dis- } \\
\text { tance was a tank. }\end{array}$ \\
\hline Trunk & biased & $\begin{array}{l}\text { Daisy was the largest circus animal of them all, and entertained the audience by pick- } \\
\text { ing up barrels with her trunk. }\end{array}$ \\
\hline Trunk & neutral & $\begin{array}{l}\text { Misty had a very strange dream, in which she was standing on a boat in the middle of } \\
\text { a jungle, and she had a trunk. }\end{array}$ \\
\hline
\end{tabular}

(Manuscript received February 12, 2008; revision accepted for publication May 28, 2008.) 